\title{
Turismo Social: o modelo do Serviço Social do Comércio (SESC)
}

\author{
Social Tourism: the model of the Social Service of Commerce (SESC) \\ Everson Emanoel Marcos de Araujo Vargas (VARGAS, E. E. M. de A.) ${ }^{*}$; \\ Tatiana Colasante (COLASANTE, T.) ${ }^{* *}$
}

\begin{abstract}
RESUMO - O presente artigo visa contextualizar e analisar o programa de turismo social desenvolvido e implementado pelo Serviço Social do Comércio (SESC), pautado nas diretrizes de sustentabilidade e promoção do acesso ao turismo para todas as pessoas. O modelo atende as demandas sociais e se mostra economicamente viável, constituindo-se em uma boa oportunidade para empresas ou empreendimentos turísticos nos períodos de baixa temporada, oferecendo serviços a baixo custo capazes de promover a atividade turística socialmente inclusiva sem representar grandes prejuízos para o prestador do serviço. Os resultados apresentados são decorrentes de pesquisa bibliográfica e documental no ano de 2018 e indicam a necessidade de se pensar em investimentos no turismo social como forma de turismo democrático e acessível a todas as pessoas na qualidade de direito social e que se desenvolve à margem do mercado turístico tradicional.
\end{abstract}

Palavras-chave: Turismo; SESC; Turismo Social; Viabilidade.

ABSTRACT - This article aims to contextualize and analyze the social tourism program developed and implemented by the Social Service of Commerce (SESC), based on sustainability guidelines and promoting access to tourism for all people. The model meets the social demands and it is economically feasible, constituting a good opportunity for companies or tourist enterprises in the periods of low season, offering services at low cost able to promote the socially inclusive tourist activity without representing great damages for the provider of the service. The results presented are based on bibliographical and documentary research accomplished in 2018 and indicate the need of thinking about investments in social tourism as a form of democratic tourism and accessible to all people as a social right and that develops on the margins of the traditional tourism market.

Key words: Tourism; SESC; Social Tourism; Viability.

\footnotetext{
Formação acadêmica: Graduando do Curso de Turismo da Universidade Estadual do Paraná (UNESPAR), Campus Apucarana. Atividade profissional: Soldado no Corpo de Bombeiros da Polícia Militar do Paraná. Endereço físico para correspondência: Rua: São Lucas, 541 - Bairro Dom Romeu Alberti - CEP: 86806-110 - Apucarana - PR - Brasil. E-mail: eversonvargas93@gmail.com

** Formação acadêmica: Graduação em Turismo e Hotelaria pela Universidade Norte do Paraná; Graduação em Geografia pela Universidade Estadual de Londrina; Especialização em Ensino de Geografia pela Universidade Estadual de Londrina; Mestrado em Geografia pela Universidade Estadual de Londrina; Doutorado em Geografia pela Universidade Estadual Paulista Campus Presidente Prudente. Atividade profissional: Professora Adjunta do Curso de Turismo da Universidade Federal do Maranhão (UFMA, Campus São Bernardo). Endereço físico para correspondência: Rua Bernardo Francisco da Cunha, 1 - CEP: 65550-000 - São Bernardo-MA - Brasil. E-mail: tati.colasante@gmail.com
} 


\section{INTRODUÇÃO}

Com as demandas sociais emergentes nos dias atuais, o turismo também passou a ser pleiteado pelas classes que, até então, não conseguiam ou sequer cogitavam realizar viagens de lazer e turismo. Empresas, empresários, entidades representativas de classe e instituições de compromisso social vêm se preocupando cada vez mais com essa crescente demanda e a consequente necessidade de oferecer opções de lazer e turismo para as classes menos favorecidas da população.

Nesse contexto, na presente pesquisa se buscou encontrar exemplos de programas de turismo social que atendessem às necessidades daqueles que não dispõem de recursos para praticar o turismo convencional e que não fossem limitados ao público interno de uma empresa ou instituição.

Partindo da definição da Organização Internacional de Turismo Social (OITS, 2018, s. p.): "O turismo social compreende quaisquer atividades que contribuam, de forma justa e sustentável, para um maior acesso a férias e atividades turísticas para todos", a pesquisa foi direcionada para o Programa de Turismo Social do Serviço Social do Comércio (SESC), uma vez que, o programa desenvolvido pela instituição possui reconhecido destaque no campo do turismo social no Brasil e contribui para a promoção de um acesso mais democrático, justo e sustentável ao lazer e ao turismo.

A pesquisa se concentrou no SESC, suas origens, suas conquistas sociais, sua expansão por todo o território nacional, as atividades desenvolvidas pela entidade, sua estrutura e ainda o surgimento e a consolidação do programa de turismo social da instituição como modelo de sucesso e eficiência. De um modo especial, se debruçou sobre a escassa bibliografia encontrada e em documentos e relatórios oficiais do SESC para descrever a trajetória do programa de turismo social da instituição no Brasil desde suas primeiras experiências até a atualidade, procurando evidenciar os princípios de promoção da paz e do bem-estar social que norteiam a atuação do Serviço Social do Comércio. 


\section{TURISMO E TURISMO SOCIAL: CONCEITOS E EVOLUÇÃO HISTÓRICA}

Cabe explicitar, inicialmente, alguns conceitos basilares para compreender de que forma o SESC vem desenvolvendo o modelo do turismo social o Brasil e a importância desse segmento como forma de inclusão social. Dessa forma, abordar-se-á alguns conceitos sobre turismo, segmentação em turismo e turismo social, bem como a contextualização histórica do desenvolvimento da atividade turística no Brasil e no mundo, tratando ainda do surgimento e evolução do turismo social e suas principais características.

\subsection{TURISMO}

Os deslocamentos humanos ocorrem desde a mais remota antiguidade. Para Dias (2005), o homem se deslocou para diversas partes do planeta, sendo motivado, principalmente, pelos movimentos instintivos dos animais e em busca de alimento por ocasião da germinação de sementes de árvores que davam frutos que lhe serviam de alimento.

Mais do que apenas o fenômeno do deslocamento humano por necessidade de alimentação, viajar sempre esteve no imaginário das civilizações desde os primórdios. Trigo (2001, p. 21) afirma que: "A relação do ser humano com as viagens é bastante antiga [...] e é reveladora de seus sentimentos mais profundos". Ao dizer que a viagem tem essa relação com os sentimentos mais profundos das civilizações, o autor transmite a ideia de que o ato de viajar faz parte da essência humana de modo que, mesmo involuntariamente, o ser humano viajaria motivado pela curiosidade e pelo instinto.

As motivações dos deslocamentos foram as mais diversas e evoluíram ao longo do tempo. Dias (2005) exemplifica que os gregos viajavam, principalmente, por motivos religiosos e esportivos. Já os romanos viajavam em busca de tratamentos de saúde, descanso, lazer e por necessidades de gestão do império. Ainda de acordo com o autor supracitado, nos séculos XVI e XVII, com as grandes navegações, a motivação principal passou a ser complementar a educação das elites, que enviavam seus jovens a lugares históricos com grande potencial cultural como forma de complementar a 
educação tradicional que recebiam e somente no século XIX o turismo chegou aos parâmetros econômicos, sociais e culturais conhecidos hoje.

O turismo se desenvolveu amplamente ao longo do século XX e de acordo com Panosso Netto (2010), o século XX pode ser chamado de o "século do turismo", porque nos últimos 100 anos o desenvolvimento do turismo atingiu o seu ápice vindo a se consolidar como um dos setores mais globalizados da economia mundial.

Segundo dados da Organização Mundial do Turismo, no ano de 2015 o turismo mundial movimentou cerca de um bilhão, duzentos e sessenta milhões de dólares, totalizando mais de um milhão, cento e oitenta milhões de chegadas de turistas nos mais diversos destinos turísticos do mundo. Ainda de acordo com a instituição, de 2010 a 2015, o fluxo turístico mundial cresceu em média 4,4\% ao ano. São pessoas do mundo todo viajando cada vez mais, movimentando a economia mundial e acionando os serviços turísticos em escala global (BRASIL, 2016).

Diversos foram os estudiosos que direcionaram seus esforços para conceituar o turismo. Barretto (2001), por exemplo, listou diversas definições de várias linhas de teorias diferentes, como a escola berlinesa e a escola polonesa, destacando aspectos comuns, divergentes e complementares entre as definições, ressaltando que os elementos mais importantes do conceito de turismo são o tempo de permanência, o caráter não lucrativo da visita e a procura por prazer por parte dos turistas.

Já para Beni (2001), o turismo é um sistema aberto composto por três grandes conjuntos, sendo eles: o das relações ambientais, o da organização estrutural e o das ações operacionais. Dentro do sistema do turismo explicado pelo autor, cada conjunto é dividido em subsistemas com funções próprias e características individuais que se correlacionam de forma interdependente refletindo positiva e negativamente nos ambientes econômico, ecológico, social e cultural. Esse sistema de turismo influencia e sofre influência do ambiente em que está inserido, de modo a se moldar de acordo com as necessidades do ambiente ou transformar o ambiente através dos impactos gerados pela atividade.

O turismo passou por grandes transformações ao longo do tempo e os estudos relacionados à atividade são relativamente recentes. A Organização Mundial do Turismo (OMT) criou um conceito de turismo que é amplamente aceito no meio acadêmico porque reúne os elementos principais apresentados por diversos estudiosos 
na tentativa de caracterizar a atividade turística. Segundo a OMT (2001, p. 38), “o turismo compreende as atividades que realizam as pessoas durante suas viagens e estadas em lugares diferentes do seu entorno habitual, por um período consecutivo inferior a um ano, com finalidade de lazer, negócios ou outras".

Torna-se imprescindível destacar que, ao limitar o período máximo de permanência e evidenciar a necessidade de o turista sair do seu entorno habitual, a OMT cria uma ferramenta que auxilia não só o mercado, mas também o meio acadêmico e o estudo científico do turismo, uma vez que os registros estatísticos passam a ter delimitações específicas para caracterizar o turismo e o turista, gerando dados mais precisos e mais próximos da realidade.

Para Barreto (2004), existem diversas abordagens técnicas e teóricas sobre o turismo, o que evidencia a amplitude de sua área de conhecimento. Uma das possibilidades de análise é sob o ponto de vista da motivação que leva o turista a viajar.

\begin{abstract}
Analisando o turismo segundo o critério da motivação, aparece uma quase infinita variedade de possibilidades, que podem ser agrupadas em duas grandes divisões, o turismo motivado pela busca de atrativos naturais e o turismo motivado pela busca de atrativos culturais. Assim, entende-se por "turismo cultural" todo turismo em que o principal atrativo não seja a natureza, mas algum aspecto da cultura humana. Esse aspecto pode ser a história, o cotidiano, o artesanato ou qualquer outro dos inúmeros aspectos que o conceito da cultura abrange (BARRETTO, 2004, p. 19-20).
\end{abstract}

Divisão similar aparece no sistema de turismo descrito por Beni (2001), no qual o autor descreve os bens turísticos como valores materiais ou imateriais que podem ser naturais ou artificiais, considerando como bem turístico artificial todo aquele que foi criado pelo homem. De acordo com o autor, é em busca dos bens e dos serviços turísticos que as pessoas viajam.

\title{
2.2 TURISMO SOCIAL
}

Conforme Almeida (2015), o termo "turismo social” surgiu na Europa do século $\mathrm{XX}$, sendo que a Alemanha foi um dos primeiros países a desenvolver essa modalidade de forma organizada e consistente, muito embora os objetivos iniciais estivessem centrados muito mais em manipulação da grande massa trabalhadora, do que no bemestar social da população. Ainda segundo a mesma fonte, após a Segunda Guerra 
Mundial, o turismo social na Alemanha, que era controlado pelo partido nazista, passou a ser delegado às Federações e Sindicatos de Operários, adquirindo o princípio de atender às classes menos favorecidas e se expandindo por toda a Europa e para o mundo.

Entre as definições de turismo social, a Organização Internacional de Turismo Social (OITS, 2018, s. p.) afirma que: "O turismo social compreende quaisquer atividades que contribuam, de forma justa e sustentável, para um maior acesso a férias e atividades turísticas para todos". A entidade considera que qualquer forma de viagem ou férias, que esteja baseada em descobertas, encontros e trocas culturais com a população local, pode contribuir para o desenvolvimento equilibrado das áreas de destino turístico e, consequentemente, para um turismo mais justo e sustentável.

De acordo com Panosso Netto e Ansarah (2009), a demanda por turismo não é distribuída igualmente entre todos os indivíduos de uma determinada população, o mais comum é que a porção da população com maior poder de compra consuma mais produtos e serviços turísticos que a porção mais pobre, criando uma participação desigual no consumo do turismo. Surge então, a necessidade de se democratizar o acesso à atividade turística.

É nesse contexto de inclusão social que o turismo social aparece como alternativa para proporcionar a prática do turismo e do lazer para a parcela da população com menor poder aquisitivo. Beni (2001) identifica que a demanda por turismo social utiliza meios de transportes mais econômicos, faz percursos mais curtos, permanece menos tempo nos locais visitados, restringe seus gastos às necessidades básicas, viaja predominantemente no período de férias, ocupa hotéis de nível médio ou albergues e utiliza sistemas de financiamento ou parcelamento da viagem. $\mathrm{O}$ autor ressalta que o turismo social só é possível em grandes proporções com a decisiva intervenção do Estado no fomento à atividade e sem a finalidade de obtenção de lucro.

O Ministério do Turismo apresenta que o turismo social é "[...] a forma de conduzir e praticar a atividade turística promovendo a igualdade de oportunidades, a equidade, a solidariedade e o exercício da cidadania na perspectiva da inclusão" (BRASIL, 2006b, p. 75). 
Inicialmente, tratado apenas como um segmento, o turismo social, devido ao seu caráter inclusivo, vem sendo abordado de uma forma mais abrangente, especialmente no que diz respeito às políticas públicas de fomento ao turismo:

[...] o Turismo Social vem sendo tratado pelo Ministério do Turismo sob uma nova visão, como uma forma de se conduzir e praticar a atividade turística, visando promover a igualdade de oportunidades, sem discriminação, acessível a todos, de maneira solidária, em condições de respeito e sob os princípios da sustentabilidade e da ética. Portanto, as premissas, estratégias e ações definidas para o Turismo Social perpassam transversalmente todos os segmentos ou tipos de turismo, como forma de se promover a inclusão pela atividade turística. (BRASIL, 2006a, p. 4)

Dentro dessa perspectiva do turismo como ferramenta de integração e inclusão e social, Krippendorf (2001), abordando os aspectos sociológicos da atividade turística com ênfase no bem-estar social, atribui ao turismo a capacidade de transformar profundamente a realidade dos praticantes a ponto de representar uma fonte de forças vitais e um reencontro com o sentido da própria existência. O mesmo autor (2001 p. 38) menciona que o direito à viagem se tornou uma reivindicação sociopolítica:

Depois do "direito às férias", o "direito à viagem" tornou-se uma reivindicação sociopolítica: todas as camadas sociais devem ter acesso à mesma. Repouso e férias tornaram-se sinônimos de turismo. A necessidade de relaxamento é reconhecida e orientada para o turismo e transformada em viagem (grifo nosso).

A relação entre as férias e o turismo aparece em muitos estudos sobre demanda turística e sazonalidade. Segundo Beni (2001), a prática do turismo em todos os seus segmentos está intimamente ligada ao período de férias dos trabalhadores, tornando o período de férias determinante na demanda pelo turismo.

Vale lembrar que a Declaração Universal dos Direitos Humanos, de 10 de dezembro de 1948 indica em seu artigo 24 que: "todo ser humano tem direito a repouso e lazer, inclusive a limitação razoável das horas de trabalho e a férias remuneradas periódicas" (UNESCO, 1998, p. 5).

Ainda nesse contexto, o direito a férias anuais remuneradas aparece no artigo $7^{\circ}$, inciso XVII, da Constituição Federal do Brasil (BRASIL,1988, p.18), assegurando ao trabalhador brasileiro, conforme os termos a seguir: 
Art. $7^{\circ}$ São direitos dos trabalhadores urbanos e rurais, além de outros que visem à melhoria de sua condição social:

[...] XVII - gozo de férias anuais remuneradas com, pelo menos, um terço a mais do que o salário normal.

Diante do exposto, é possível concluir que o turismo é um complexo fenômeno social que possui características de direito fundamental do ser humano e tem o pressuposto de ser protagonista na promoção da inclusão social e da igualdade entre as pessoas. Segundo Ferreira (1996 apud Giareta, 2003, p. 28):

Turismo, por si só é um fato social. Não haveria turismo que não fosse atividade social, quer se ocupasse de negócios, desportes, religião, cultura, extensão profissional, arqueologia, espeleologia, ecologia, ou fosse meramente contemplativo. Tudo isso é atividade turística. O Turismo resulta da interação social permanente de estímulo contra estímulo de cultura em busca de cultura, ou ela em choque, até mesmo um impulso de ascensão social, acomodando-se ou sobrepujando o homem contra o próprio homem.

Banducci Junior e Barretto (2001, p. 8), explicam ainda que o turismo “é um fenômeno social também porque faz parte das necessidades criadas pelo mundo moderno". Se os benefícios proporcionados pela atividade turística são resultantes dessas múltiplas interações sociais, é, portanto, imprescindível que todas as pessoas tenham acesso a esses benefícios em seu tempo livre.

De acordo com Rua (2006), o turismo oferece possibilidades de fortalecimento tanto do capital físico, quanto do capital humano das localidades receptoras. Isso porque para o desenvolvimento da atividade é necessário que se invista tanto em infraestrutura como transportes, meios de hospedagem, serviços de alimentação e entretenimento, quanto em educação e capacitação profissional.

Quando o planejamento do turismo é abrangente e contempla todos os setores, incluindo a comunidade local, proporciona não só perspectivas e oportunidades de desenvolvimento econômico, mas também estimula o interesse pelas viagens turísticas nos indivíduos da comunidade. Porém, as disparidades culturais entre turista e comunidade local, e o alto poder aquisitivo dos turistas que frequentam determinadas localidades, podem dar a impressão de que a prática do turismo seja inviável para aqueles moradores locais que possuem menor poder aquisitivo. Torna-se necessário,

\footnotetext{
${ }^{1}$ FERREIRA, F. L. V. Turismo Social. In: Confederação Nacional do Comércio. São Paulo: Conselho de Turismo, Coletânea Turística, 1996.
} 
portanto, oferecer produtos e serviços turísticos com o objetivo de facilitar o turismo interno das classes menos favorecidas economicamente (BENI, 2001).

A alternativa para fornecer produtos e serviços turísticos acessíveis às classes menos favorecidas é o turismo social. O Código Mundial de Ética do Turismo elaborado pela OMT em 1999, prevê o desenvolvimento do turismo social com o apoio das autoridades públicas, em caráter associativo, visando o acesso da maioria dos cidadãos ao lazer e as férias, promovendo um turismo responsável e sustentável e possibilitando que qualquer pessoa consiga exercer o seu direito de utilizar seu tempo livre no lazer e nas viagens (BRASIL, 2018).

Como o público alvo do turismo social é a população de menor renda, essa modalidade de turismo deve ser desenvolvida com o amplo apoio da iniciativa pública e de associações. Alguns autores fazem uma ligação direta entre a promoção do turismo social e as empresas e corporações que possuem grande contingente de colaboradores, atribuindo a estas o papel de promover e organizar o turismo social para seus empregados, como se pode ver no conceito de Oliveira $(2001$, p. 81$)$ sobre turismo social:

\footnotetext{
Praticados por pessoas de baixa renda, normalmente operários que, não podendo arcar com as despesas de seu próprio bolso, contam com a ajuda das fábricas em que trabalham. Elas organizam a viagem e cobram as despesas dos empregados a longo prazo, em descontos mensais nas folhas de pagamento. Esse tipo de turismo acontece geralmente em finais de semana, em locais que sofrem sazonalidade, em épocas de baixa temporada, quando os preços dos hotéis caem consideravelmente e em locais não muitos distantes das fábricas, para não encarecer o custo do transporte.
}

Dessa forma, o turismo social deve ser uma preocupação de todos os atores envolvidos nos mais diversos setores da atividade turística e deve ser proporcionado através de políticas públicas de incentivo à prática do turismo como opção de lazer no tempo livre, do envolvimento de associações e empresas com o objetivo de facilitar o acesso ao turismo, bem como opções de parcelamento ou financiamento das viagens, e também da oferta de taxas e serviços mais baratos por parte das empresas prestadoras de serviços turísticos. Para estas, inclusive, o turismo social pode representar uma boa oportunidade de negócios, uma vez que, em determinadas épocas do ano, a procura tradicional pelo turismo diminui, caracterizando uma baixa temporada. 
De acordo com Santos e Kadota (2012, p. 254), “em muitos lugares, parte das empresas chega a paralisar as atividades durante a baixa temporada, dispensando temporariamente todos os empregados". As empresas e prestadores de serviços turísticos podem aproveitar esse período de baixo fluxo de turistas para oferecer tarifas e serviços mais baratos que permitam a prática do turismo social. Dessa forma, mantémse estável o fluxo turístico mesmo em períodos em que, tradicionalmente, há uma baixa procura.

Como já observado em Beni (2001), a demanda do turismo social utiliza dos serviços de hospedagem, alimentação e transporte mais econômicos, restringe seus gastos às necessidades básicas da viagem, também permanece períodos mais curtos nas localidades receptoras e busca os destinos não muitos distantes do seu entorno habitual. Diante dessas características, pode-se fazer uma ligação direta entre turismo social e turismo doméstico, aquele em que o turista viaja dentro do território nacional do país em que reside e que tem custos reduzidos em relação ao turismo internacional.

A OITS $(2018$, s. p.) lista a "promoção do turismo social como força motriz para o desenvolvimento do turismo doméstico" como um dos desafios da entidade para o planejamento e implementação de políticas públicas de turismo social dentro dos países membros da organização.

A partir dessa ligação entre turismo social e turismo doméstico, observa-se um cenário muito promissor para o desenvolvimento do mercado interno do turismo no Brasil, promovendo desenvolvimento econômico, distribuição de renda e inclusão social. O turismo doméstico pode representar uma excelente oportunidade de negócios para toda a indústria do turismo, bem como uma oportunidade única para o desenvolvimento e ampliação de iniciativas voltadas ao turismo social.

\subsection{TURISMO SOCIAL NO BRASIL}

Depois da Alemanha, os países europeus foram desenvolvendo, ao longo do século XX, modelos de turismo social de acordo com suas particularidades políticas e econômicas. De acordo com Almeida (2015), foi em 1963 e com o objetivo de promover o turismo social a nível internacional, que surgiu a entidade de turismo social mais importante do mundo, o Bureau International de Tourisme Social (BITS), com 
sede em Bruxelas, na Bélgica. Ainda segundo o autor, o BITS deu origem à Organização Internacional de Turismo Social (OITS).

A OITS, que tem como lema "um turismo justo e sustentável para todos", está presente em 57 países através de seus membros afiliados (OITS, 2018). Tendo a Europa como ponto de partida, a Organização Internacional de Turismo Social expandiu as suas atividades também para as Américas, África e Ásia (OITS, 2018). No Brasil, os membros afiliados são Araribá Turismo \& Cultura e Flanar Turismo, ambas operadoras de turismo cultural e, ainda, o Serviço Social do Comércio (SESC), através do seu departamento nacional (OITS, 2018). Embora seja uma realidade em muitos países desenvolvidos, o turismo social no Brasil ainda é pouco conhecido e pouco praticado. Para Trigo (2001, p. 40):

O turismo e o lazer social são viáveis, têm uma importância sociopolítica e podem ser deliciosos para os consumidores e lucrativos para os produtores. Nos países desenvolvidos, ele é uma realidade, mas nos países subdesenvolvidos ainda é uma utopia, um sonho a ser realizado. Um assunto teórico para livros, jornais ou revistas.

Ao relatar as experiências de sucesso referentes ao turismo social na França, Almeida (2012) ressalta que apesar das diferenças socioculturais com o Brasil, há que se pensar o quão incipiente estão as iniciativas no país no tocante a este segmento. Neste aspecto, destaca-se que as possibilidades para o desenvolvimento do turismo social no Brasil, tendo como base o turismo doméstico, são muitas, tendo em vista que o mercado brasileiro do turismo está aquecido e apresenta números bastante expressivos.

Dados divulgados no Anuário 2018 da Associação Brasileira de Operadoras de Turismo - BRAZTOA, demonstram que, no ano de 2017 o turismo doméstico movimentou cerca de 4,3 milhões de turistas no Brasil, totalizando um montante de $\mathrm{R} \$$ 10,8 bilhões na economia brasileira (BRAZTOA, 2018). Levando em conta que esses dados representam apenas aqueles turistas que utilizaram os pacotes oferecidos pelas operadoras de turismo, tem-se dados ainda mais significativos se forem contabilizados os gastos daqueles turistas que viajam em pequenos grupos, com veículos particulares, nas férias, finais de semana ou feriados prolongados.

Segundo estudo feito pelo Ministério do Turismo em parceria com a Fundação Getúlio Vargas, somente no mês de maio de 2018, com a ocorrência de dois feriados prolongados (dia $1^{\circ}$ de maio - dia do trabalhador e 31 de maio - dia de Corpus Christi) o 
turismo doméstico movimentaria cerca de R $\$ 9$ bilhões, totalizando cerca de 9 milhões de viagens em todo o território nacional (BRASIL, 2018). Tal fluxo de pessoas deslocando-se dentro do território nacional aciona toda a infraestrutura turística e movimenta o mercado interno do turismo.

Essa é apenas uma amostra do potencial que o turismo doméstico tem de movimentar a economia e promover o desenvolvimento local em outras áreas como distribuição de renda e valorização da cultura, proporcionando um cenário propício para o desenvolvimento do turismo social. O problema, segundo Trigo (2010), é que a desigualdade social no Brasil acabava restringindo a prática do turismo à uma pequena parcela da população que pode pagar os altos preços das viagens, deixando a população com menor poder aquisitivo sem opções de turismo.

Para Beni (2001), seria papel do Estado a promoção do turismo social para todas as pessoas através do investimento social, inclusive com a implantação de programas que permitam que as classes menos favorecidas economicamente possam realizar o turismo, usufruindo dos benefícios da atividade e movimentando principalmente o mercado interno.

Já na concepção de Oliveira (2001), as grandes empresas e corporações é que teriam a responsabilidade de promover o turismo social para os seus colaboradores. Independentemente de quem exerça o papel principal de promoção do turismo social, considera-se ficar claro ser necessário o envolvimento de toda a cadeia produtiva do turismo. Tentando abranger todos os pontos de vista, o Ministério do Turismo lança um novo olhar sobre o papel de promover o turismo social:

O Ministério do Turismo entende que o papel do Estado é de agente incentivador e coordenador no que diz respeito à participação de outros órgãos de governo, da sociedade civil organizada e do setor privado em relação ao turismo, com objetivos claramente definidos de recuperação psicofísica e de ascensão sociocultural e econômica dos indivíduos. Assim, não são explicitadas as questões de subsídios e subvenções públicas como pressuposto para caracterizar o Turismo Social (não que não devam existir, apenas não devem ser estes os elementos diferenciais). Nessa perspectiva, procura-se desenvolver o turismo com vistas à inclusão, privilegiando a ótica de cada um dos distintos atores envolvidos na atividade: o turista, o prestador de serviços, o grupo social de interesse turístico e as comunidades residentes nos destinos. (BRASIL, 2006b, p. 5).

A partir dessa concepção do envolvimento de todos no turismo social, o Ministério do Turismo (BRASIL, 2006b) ainda reforça que pela ótica do turista, o foco 
estaria nas pessoas com renda insuficiente para usufruir da atividade turística e, por isso, têm suas possibilidades de lazer limitadas. Pela ótica dos prestadores de serviços, a preferência é dos pequenos e microempreendedores e, em relação aos grupos de interesse turístico, a ênfase está nas condições sociais e culturais das comunidades que apresentam atrativos turísticos de alto valor cultural (BRASIL, 2006b).

Desta forma, o turismo social passa a ser visto não apenas como segmento, mas como uma abordagem transversal entre os diversos tipos de segmentos no turismo e como uma forma inclusiva de conduzir e praticar a atividade turística com o objetivo principal de distribuir melhor os benefícios. Segundo o Ministério do Turismo (BRASIL, 2006b, p. 7):

O Turismo Social compreende uma forma de turismo. A forma de conduzir refere-se à maneira de entender, conceber e direcionar políticas e orientar os processos que levam ao desenvolvimento do turismo. A forma de praticar refere-se às circunstâncias de acesso à experiência turística. Ambas devem ser mediadas pela premissa da ética (nas relações turísticas comerciais, com as comunidades receptoras e com o ambiente) e da sustentabilidade no seu sentido mais amplo (econômica, social, cultural, ambiental e política).

De acordo com Zapata e Zapata (2006, p. 60): “em geral, as atividades turísticas voltadas para os turistas com menor nível de renda são mais geradoras de emprego". Essa visão sobre o turismo social é muito importante para o desenvolvimento e disseminação dessa forma recente de se pensar o turismo no Brasil. É preciso reconhecer que o turismo social não é voltado somente para a promoção do lazer e do turismo para os turistas de menor poder aquisitivo, mas o fluxo provocado por esse tipo de turismo também tem potencial para alavancar o desenvolvimento econômico e estrutural da cadeia produtiva da "indústria turística interna", criando mais postos de trabalho, fortalecendo os micro e pequenos empresários do turismo e gerando renda para as comunidades receptoras.

Embora o turismo social venha se consolidando como essa forma recente de pensar, planejar e praticar o turismo no Brasil, sua aplicação prática ainda é muito pouco observada. Pode-se confirmar esse panorama em Beni (2001, p. 421):

No Brasil, notam-se iniciativas isoladas de empresas e associações de classe, voltadas ao fomento do turismo socializado, ao passo que a vasta maioria preocupa-se tão somente em intensificar o turismo de massa ou convencional, eis que este garante o retorno rápido dos investimentos no setor. Podemos afirmar a inexistência de uma política que vise especificamente atender as classes populares na prática do Turismo. 
Algumas poucas iniciativas e projetos de turismo social aparecem como precursoras do tema, podendo-se citar, por exemplo, alguns projetos de extensão acadêmica de cursos de turismo pelo Brasil. Desde 2001, os alunos do curso de Turismo da Escola de Comunicações e Artes da Universidade de São Paulo (USP), desenvolvem um projeto de turismo social intitulado "Rosa dos Ventos", no qual planejam e executam roteiros turísticos e atividades artísticas, culturais e lúdicas, principalmente com jovens em vulnerabilidade social (GOUVEIA, 2011).

Mais recentemente, a Universidade Federal Fluminense (UFF) também lançou um projeto de turismo social, criado em 2014, porém voltado apenas para o público interno da universidade, oferecendo, excursões pela cidade de Niterói-RJ, onde fica a sede da UFF, para servidores e alunos que comprovam baixa renda (FONSECA, 2018).

São exemplos de iniciativas pioneiras que demonstram que o turismo social, ainda que timidamente, vem ganhando espaço e visibilidade. Em ambos os casos os gastos das viagens são subsidiados pelas entidades, que arrecadam dinheiro de fontes alternativas como promoções e vendas de produtos de artesanato ou alimentação.

Almeida (2016) ressalta que, no Brasil, as iniciativas do sistema "S", especialmente o Serviço Social do Comércio - SESC inserem-se na promoção do lazer e do turismo social. A iniciativa do SESC talvez seja a mais bem-sucedida quando se fala de sustentabilidade do mercado turístico. Isso porque aciona e movimenta economicamente toda a estrutura de serviços turísticos que inclui transporte, hospedagem, alimentação e alguns serviços adicionais, propondo um custo acessível à população (SESC, 2012).

\section{O SERVIÇO SOCIAL DO COMÉRCIO (SESC): PANORAMA GERAL E O MODELO DE TURISMO SOCIAL}

O Serviço Social do Comércio (SESC) surgiu no período de transição entre o fim do Estado Novo de Getúlio Vargas e o processo de democratização do Brasil (SESC, 2018). A criação do SESC é descrita pela primeira vez na Carta da Paz Social, um documento de janeiro de 1946, elaborado a partir da Conferência de Teresópolis, que aconteceu de 1 a 6 de maio de 1945 e reuniu empregadores e representantes das 
classes produtoras do país na tentativa de conter as tensões existentes na época entre trabalhadores e empresários (SESC, 2012).

A Carta da Paz Social é um importante marco na história da classe trabalhadora do Brasil. Nela foram elencados os princípios de iriam nortear as relações entre empregados e empregadores em busca de uma sólida paz social (SESC, 2012). Foi previsto no documento a criação de um fundo social.

[...] 4) Com o objetivo de atender às necessidades sociais urgentes e de propiciar aos trabalhadores do campo e da cidade maior soma de bem-estar e igualdade de oportunidade, propõem-se os empregadores a criar um Fundo Social a ser aplicado em obras e serviços que beneficiem empregados de todas as categorias, e em assistência social em geral, repartindo com os institutos existentes as atribuições assistenciais e de melhoramento físico e cultural da população. O objetivo do Fundo Social é promover a execução de medidas que, não só melhorem continuamente o nível de vida dos empregados, mas lhe facilitem os meios para seu aperfeiçoamento cultural e profissional (SESC, 2012, p. 13).

O documento detalha ainda que a arrecadação de recursos para o Fundo Social deve ser feita através de contribuições obrigatórias de cada empresa agrícola, industrial, comercial ou de outra natureza, de modo a atender às necessidades do plano assistencial previsto sem a dependência da gestão pública (SESC, 2012). Ainda de acordo com o SESC, com a edição da Carta da Paz social e a previsão da criação do Fundo Social, as ações previstas na Conferência de Teresópolis em busca da harmonia social no Brasil, começaram a ganhar força e estrutura.

De acordo com Lupion (2017), o Sistema "S", que controla a distribuição dos recursos do Fundo Social ${ }^{2}$, começou a ser estruturado em 1942, com o intuito de oferecer aos trabalhadores formação e atualização profissional e serviços culturais e de lazer, sem depender da gestão ou de recursos públicos.

Segundo o SESC (2018), a criação oficial da entidade se deu pelo Decreto-Lei $\mathrm{n}^{\circ} 9.853$ de 13 de setembro de 1946 e a primeira unidade no Brasil foi inaugurada em 3 de outubro de 1946, no bairro Engenho de Dentro na cidade do Rio de Janeiro. Cheibub (2012) aponta que uma das primeiras iniciativas do Sesc articuladas ao turismo foi

\footnotetext{
${ }^{2} \mathrm{O}$ sistema S é composto por nove entidades: Serviço Nacional de Aprendizagem Industrial (SENAI), Serviço Nacional de Aprendizagem Rural (SENAR), Serviço Nacional de Aprendizagem do Cooperativismo (SESCOOP), Serviço Nacional de Aprendizagem do Comércio (SENAC), Serviço Nacional de Aprendizagem do Transporte (SENAT), Serviço Brasileiro de Apoio às Micro e Pequenas Empresas (SEBRAE), Serviço Social da Indústria (SESI), Serviço Social de Transporte (SEST) e Serviço Social do Comércio (SESC). (LUPION, 2017, s.p.).
} 
buscar uma área onde os trabalhadores pudessem passar as férias. Com isso, foi escolhido o município litorâneo de Bertioga-SP, onde foi construído o Centro de Férias Sesc Bertioga em 1948. Nos anos seguintes, o SESC começou a expandir suas atividades através da instalação de unidades executivas em outros estados brasileiros.

O Serviço Social do Comércio desenvolve suas ações institucionais com foco em ações educativas, eficácia, qualidade, acessibilidade e responsabilidade ambiental. A missão é, segundo a própria entidade (SESC, 2017, p. 24), "promover ações socioeducativas que contribuam para o bem-estar social e a qualidade de vida dos trabalhadores do comércio de bens, serviços e turismo, de seus familiares e da comunidade, para uma sociedade justa e democrática".

De acordo com o SESC (2017), a instituição registrou, nos programas de educação, saúde, cultura, lazer, e assistência, um total de oitocentos e sete milhões, oitocentos e vinte e quatro mil, seiscentos e oitenta e quatro atendimentos no ano de 2016, em todo o território nacional. Levando em conta que, segundo o Instituto Brasileiro de Geografia e Estatística - IBGE, em 2016, a estimativa da população brasileira era de pouco mais de duzentos e sete milhões de habitantes, pode-se concluir que o SESC tem prestado um relevante e eficiente serviço para a sociedade brasileira e, como prevê em sua missão, tem contribuído para a construção de uma sociedade mais justa e democrática.

No que se refere especificamente ao programa de turismo social do SESC, o modelo surgiu nos anos de 1970, em meio a uma grande expansão das atividades da instituição. Nessa mesma década foram criados novos centros de lazer e turismo, ginásios e quadras de esportes, piscinas, hotéis e estâncias (SESC, 2018). Em 1980, o SESC São Paulo se associou à Organização Internacional de Turismo Social (OITS). Posteriormente, se associaram a OITS, outras unidades regionais e também o Departamento Nacional (SESC, 2018).

Desde então o SESC, através do seu programa de turismo social, vem se tornando referência de boas práticas que proporcionam a democratização do acesso ao lazer e ao turismo social. Segundo o SESC (2017), no ano de 2016, foram atendidas, nas excursões e passeios organizados pela instituição, mais de 223 mil pessoas em todo o Brasil. Se forem considerados todos os atendimentos relacionados ao turismo social, 
como hospedagem nos hotéis, estâncias e centros de lazer, por exemplo, chegar-se-á ao total de aproximadamente 3 milhões de atendimentos em todo o território nacional.

O programa de turismo social desenvolvido pelo Serviço Social do Comércio é reconhecido pela sociedade e citado por vários autores como iniciativa bem-sucedida e pioneira no turismo social. Dentre eles pode-se citar: Almeida (2015, 2016), Beni (2001) e Cheibub (2012). Almeida (2015, p. 351), inclusive, coloca o modelo de turismo social do SESC, como modelo de gestão a ser seguido no Brasil:

As diversas ações empreendidas pelo Sesc ao longo dos últimos 50 anos explicam claramente por que a entidade - que, com muita criatividade e bom senso, conseguiu equacionar as principais características do turismo social: viagens diferenciadas do ponto de vista conceitual e operacional e baixo custo - deve ser tomada como modelo de gestão na promoção do turismo social no Brasil.

Com um programa de turismo social levado a sério e que alcança resultados cada vez mais significativos, a entidade planeja ampliar o atendimento a curto e a longo prazo (SESC, 2017). As diretrizes do SESC para o quinquênio 2016-2020 preveem o aperfeiçoamento das ações de turismo social, com foco na perspectiva educativa e na vivência da cidadania, primando pela valorização da pessoa humana, pela preservação do meio ambiente e do patrimônio histórico cultural e buscando uma forma mais dinâmica do processo de democratização da atividade turística (SESC, 2017). A entidade, enquanto membro da OITS, compartilha do ideal de buscar um turismo justo e sustentável para todos.

O SESC está presente em cerca de dois mil e duzentos municípios em todas as regiões do país, possuindo unidades fixas e móveis de atendimento como centros de atividades, meios de hospedagem, sedes educacionais, teatros e bibliotecas (SESC, 2012). A instituição exerce atividades nas áreas da educação, da saúde, da cultura e do lazer, sendo que este último inclui o programa de Turismo Social, tratado pelo SESC como sendo um dos pilares da sua missão institucional (SESC, 2012).

Para o Sesc, o Turismo Social é uma atividade que visa proporcionar integração social, novas oportunidades de lazer, enriquecimento cultural, exercício da cidadania, acessibilidade e diversão às pessoas. [...] A missão do Sesc é promover o turismo para todos, uma atividade geradora de ampla gama de recursos e benefícios para as cidades visitadas, que podem investir em seu potencial turístico e, assim, movimentar a economia local (SESC, 2012, p. 87). 
O programa de turismo social desenvolvido pelo Serviço Social do Comércio no Brasil é um exemplo de boas práticas com a finalidade de promover a inclusão social e a sustentabilidade através da atividade turística (SESC, 2018). As atividades realizadas priorizam também o enriquecimento cultural dos participantes e o aproveitamento da experiência turística em toda a sua complexidade, resultando num modelo econômico e ambientalmente sustentável e cultural e socialmente abrangente e inclusivo. De acordo com o SESC (2018), a entidade possui uma central de viagens que planeja e executa as ações de turismo social, oferecendo ao participante diversos pacotes para destinos dentro do território nacional e possibilitando o pagamento parcelado das despesas da viagem.

\section{CONSIDERAÇÕES FINAIS}

Já no início do processo de estruturação do presente artigo de pesquisa foi possível notar que a bibliografia que trata de turismo social ainda se encontrava escassa ou quase inexistente em língua portuguesa. Poucos autores brasileiros abordaram o tema e, quando o fizeram, realizaram apenas breves explicações sobre a origem do termo ou trataram do turismo social apenas para exemplificar modalidades dentro de algum trabalho sobre segmentação turística. Logo, para superar esse obstáculo, foi de fundamental importância recorrer ao material disponibilizado pela Organização Internacional de Turismo Social (OITS) e pelo Ministério do Turismo para que o trabalho fosse enriquecido do ponto de vista histórico e conceitual do turismo social.

Vencida a fase de estruturação histórica e conceitual do turismo social no Brasil e no mundo, foi possível compreender que o turismo social é uma modalidade que se desenvolve à margem do mercado turístico convencional, praticamente sem visibilidade e quase sempre restrito ao público interno de empresas ou instituições que ousam oferecer o lazer e a viagem, com baixo custo, sem objetivar o lucro e democratizando o acesso ao turismo e ao lazer para que seus membros ou colaboradores possam usufruir dos benefícios da atividade turística.

Nessa busca por exemplos bem-sucedidos de iniciativas no campo do turismo social, o Serviço Social do Comércio aparece como pioneiro e como talvez o único 
exemplo de sucesso do ponto de vista da sustentabilidade da própria atividade. O objetivo não é o lucro, mas o sistema precisa de entrada de recursos para se sustentar, o SESC então, investe em infraestrutura própria de hotéis, instâncias e centros de lazer e busca parcerias no mercado turístico tradicional de transporte, hospedagem e alimentação, com foco nos períodos de baixa temporada, quando os preços são relativamente mais baixos.

O resultado é um produto turístico de qualidade, com preço acessível e formas de pagamento facilitadas para o público em geral, com descontos adicionais para os comerciários do SESC e seus dependentes e que atrai cada vez mais pessoas para o programa de turismo social da instituição. Com a estrutura própria de hotéis e as parcerias firmadas com alguns setores da atividade turística a capacidade de ofertar pacotes de viagens de baixo custo e com pagamento facilitado se torna o grande diferencial.

O sucesso do modelo de turismo social implementado pelo SESC pode servir como um agente motivador para que outras empresas ou empreendimentos do mercado turístico possam oferecer opções de um turismo acessível para todas as pessoas, isso porque além dos valores sociais implícitos, o modelo do SESC também é economicamente sustentável.

O turismo social, ainda muito marginalizado pelo mercado, poderia se tornar mais uma opção de diversificação do produto turístico, tendo em vista que os períodos de baixa temporada podem ser aproveitados para a oferta do turismo social, proporcionando a democratização do acesso ao lazer e ao turismo e ao mesmo tempo garantindo o faturamento das empresas ou empreendimentos.

Se o programa de turismo social do SESC é suficiente para atender à demanda emergente do turismo social, ou ainda, se é capaz de democratizar ainda mais o acesso ao lazer e ao turismo pode ser um objeto de estudo interessante para ser abordado em pesquisas futuras. Aliás, com a escassez de estudos sobre o turismo social, toda contribuição sobre o tema será de grande aproveitamento para a comunidade científica do turismo. Com este trabalho, espera-se ter contribuído para que o turismo social seja visto como uma modalidade turística sustentável não só do ponto de vista social, mas também nos aspectos ambientais, culturais e econômicos. 


\section{REFERÊNCIAS}

ALMEIDA, M. V. de. Turismo Social. In: TRIGO, L. G. G.; PANOSSO NETTO, A.; CARVALHO, M. A.; PIRES, P. dos S. P. (orgs.). Análises regionais e globais do turismo brasileiro. São Paulo: Roca, 2015, p. 345-354.

Turismo Social na França. Turismo \& Sociedade, Curitiba, v. 5, n. 1, p. 340343, abr. 2012.

Turismo social: reflexões e práticas no Brasil. Revista Turismo \& Desenvolvimento, São Paulo, n. 26, p. 141-154, 2016.

BANDUCCI JUNIOR, Á.; BARRETTO, M. Introdução. In: Turismo e identidade local: uma visão antropológica. 5. ed. Campinas: Papirus, 2001, p. 7-20.

BARRETTO, M. Turismo e legado cultural: as possibilidades do planejamento. 5. ed. Campinas: Papirus, 2004.

Manual de iniciação ao estudo do turismo. 11. ed. Campinas: Papirus, 2001.

BENI, M. C. Análise Estrutural do Turismo. 6. ed. São Paulo: SENAC, 2001.

BRASIL. Constituição (1988). Constituição da República Federativa do Brasil. Brasília, DF, 1988. 292 p.

BRASIL. Ministério do Turismo. Estatísticas e Indicadores - Turismo Mundial. 2016. Disponível em: <http://www.dadosefatos.turismo.gov.br/estat\%C3\%ADsticas-eindicadores/estat\%C3\%ADsticas-e-indicadores-turismo-mundial.html>. Acesso em: 30/04/2018.

Turismo, 2006a.

Segmentação do turismo: marcos conceituais. Brasília: Ministério do

Turismo Social: diálogos do turismo: uma viagem de inclusão. Rio de Janeiro: IBAM, 2006b.

BRASIL. Ministério do Turismo. Código de Ética do Turismo. 1999. Disponível em: <http://www.turismo.gov.br/sites/default/turismo/o_ministerio/publicacoes/downloads_ publicacoes/PREVIEW_MTUR_Codigo_de_Etica_Turismo_120_210mm_Portugues.p df>. Acesso em: 30/03/2018.

BRAZTOA. Associação Brasileira das Operadoras de Turismo. Anuário BRAZTOA 2018. Disponível em: <http://braztoa.com.br/?post_type=publicacao\&p=6182>. Acesso em: 02/05/2018. 
CHEIBUB, B. L. Reflexões Sobre o Turismo Social a partir da História Institucional do Serviço Social do Comércio (Sesc). In: SEMINÁRIO DE PESQUISA EM TURISMO DO MERCOSUL, 7, 2012, Caxias do Sul. Anais... Caxias do Sul: Universidade de Caxias do Sul, 2012.

DIAS, R. Introdução ao Turismo. São Paulo: Atlas, 2005.

FONSECA, G. Conheça o Turismo Social UFF: Projeto que oferece passeios para alunos e funcionários da universidade. Jornal de Comunicação Social da UFF. 2018. Disponível em: <http://www.jornalocasarao.com/2018/07/conheca-o-turismo-social-uffprojeto.html>. Acesso em: 30/04/2018.

GIARETA, M. J. Turismo da Juventude. Barueri: Manole, 2003.

GOUVEIA, M. E. A. B. Alunos têm projeto de turismo social "Rosa dos Ventos". 2016. Disponível em: < http://www3.eca.usp.br/node/2192>. Acesso em: 30/04/2018.

IBGE. Instituto Brasileiro de Geografia e Estatística. Estimativas da população residente no Brasil e unidades da federação com data de referência em $1^{\circ}$ de julho de 2016. Disponível em: <https://www.ibge.gov.br/estatisticas-novoportal/downloadsestatisticas.html>. Acesso em: 18/06/2018.

KRIPPENDORF, J. Sociologia do Turismo: para uma nova compreensão do lazer e das viagens. 3. ed. São Paulo: Aleph, 2001.

LUPION, B. O que é o sistema S, quanto custa e a quem beneficia. Nexo Jornal Ltda. Disponível em: <https://www.nexojornal.com.br/expresso/2017/02/18/O-que\%C3\%A9-o-Sistema-S-quanto-custa-e-a-quem-beneficia>. Acesso em: 15/06/2018.

OITS. Organização Internacional de Turismo Social. Turismo justo e sustentável para todos. Disponível em: <http://www.oits-isto.org/oits/public/index.jsf>. Acesso em: $15 / 06 / 2018$.

OLIVEIRA, A. P. Turismo e desenvolvimento: planejamento e organização. 3. ed. São Paulo: Atlas, 2001.

OMT. Introdução ao turismo. São Paulo: Roca, 2001.

PANOSSO NETTO, A. O que é turismo. 1. ed.São Paulo: Brasiliense, 2010.

Turismo Básico. 5. ed. São Paulo: SENAC, 2001.

PANOSSO NETTO, A.; ANSARAH, M. G. dos R. Segmentação em Turismo: panorama atual. In: Segmentação do mercado turístico: estudos, produtos e perspectivas. Barueri: Manole, 2009, p. 19-44.

PANOSSO NETTO, A.; GAETA, C. G. (orgs). Turismo de Experiência. São Paulo: SENAC, 2010, p. 21-42. 
RUA, M. das G. Turismo e Políticas Públicas do Turismo. In: Turismo Social: diálogos do turismo: uma viagem de inclusão. 1. ed. Rio de Janeiro: IBAM, 2006, p.17-38.

SANTOS, G. E. de O.; KADOTA, D. K. Economia do Turismo. 1. ed. São Paulo: Aleph, 2012.

SERVIÇO SOCIAL DO COMÉRCIO. O Sesc comemora sete décadas promovendo cidadania. 2018. Disponível em: <https://www.sescpr.com.br/2018/01/sesc-paranacelebra-70-anos/>. Acesso em: 27/06/2018.

Relatório estatístico do SESC 2016: Brasil. Departamento Nacional. Rio de Janeiro: SESC, 2017.

Diretrizes para o quinquênio 2016-2020. Rio de Janeiro: SESC, 2016.

Guia de Férias Sesc. Rio de Janeiro: SESC, 2012.

TRIGO, L. G. G. A viagem como experiência significativa. In: Turismo de experiência. São Paulo: Editora SENAC, 2010.

UNESCO. Declaração Universal dos Direitos Humanos. 1998. Disponível em: <https://unesdoc.unesco.org/ark:/48223/pf0000139423>. Acesso em: 30/04/2018.

ZAPATA, J. C.; ZAPATA, T. R. Turismo, Valorização da Brasilidade e Construção do Capital Social. In: Turismo Social: diálogos do turismo: uma viagem de inclusão. Rio de Janeiro: IBAM, 2006, p.38-75.

Recebido em: 05-11-2018.

Aprovado em: 05-12-2018.

Versão finalizada para publicação em: 16-03-2019. 